\title{
ACCESO AL DERECHO A LA JUSTICIA CON LA IMPLEMENTACIÓN DEL USO DE LAS TECNOLOGÍAS DE LA INFORMACIÓN Y LAS COMUNICACIONES (TIC) EN LA TUTELA DE LOS DERECHOS DEL CONTRIBUYENTE
}

\author{
Acces to right of justice with the implementation of the use of Information Technology \\ and Communications (ICT) in the protection of taxpayer rights
}

\author{
Jessica Cristina Romero Michel ${ }^{1}$ \\ Mario Cruz Bentura
}

\begin{abstract}
Sumario:
I. Introducción. II. La defensa de los derechos del contribuyente. III. La PRODECON como ombudsman del contribuyente. IV. El derecho de acceso a la justicia con la implementación del uso de las TIC. V. El uso de las TIC en materia tributaria. V.1. Juicio en línea contencioso administrativo federal. V.2. Recurso de revocación en línea. VI. El derecho de acceso a la justicia con la implementación del uso de las TIC en la PRODECON. VII. Conclusiones. VIII. Fuentes de Información.
\end{abstract}

Resumen. Los servicios públicos que ofrece el Estado se han ido transformando y adaptando a los avances que hoy implican incorporar la innovación tecnológica. Razón por la que el acceso a la justicia con la implementación de las TIC además de ser un derecho fundamental tutelado por el Estado; también es un derecho que debe ser alcanzable para todos, con independencia de sus circunstancias personales, economía o conocimientos. Además, debe traducirse como el resultado de una política pública encaminada a cubrir la oferta del servicio. Por eso, en esta investigación se analiza el alcance que ésta tiene en materia de derechos del contribuyente.

Palabras clave. Derechos humanos. Acceso a la Justicia. Derechos del Contribuyente, Tecnologías de la Información y la Comunicación (TIC).

Abstract. Public services offered by the State have been changing and adapting to advances that today involves incorporating technological innovation. Therefor access to justice with the use of ICT in addition to being a fundamental right protected by the State; it is also a right that should be achievable for all, independently of their personal circumstances, economy or knowledge. Also, it should be translated as the result of public policy to cover the service offer. Finally, in this research, we analyze the extent that access to digital justice has on the rights of the taxpayers.

Key words. Human rights. Access to Justice. Taxpayer Rights. Information and Communications Technologies (ICT).

\footnotetext{
${ }^{1}$ Doctora en Derecho y Profesora Investigadora de Tiempo Completo de la Facultad de Derecho de la Universidad de Colima, integrante del CA Derecho y Tecnología, con perfil deseable PRODEP y miembro del Sistema Nacional de Investigadores (SNI) de CONACyT, jessica_romero@ucol.mx

${ }^{2}$ Estudiante del $9^{\circ}$ semestre de la Licenciatura en Derecho de la Facultad de Derecho de la Universidad de Colima y participante del proyecto de investigación financiado por PRODEP "El uso de las Tecnologías de la Información y las Comunicaciones (TIC) en la Administración de Justicia en un marco de equidad."
} 


\section{INTRODUCCIÓN}

En el ámbito internacional se observa un cambio en el entendimiento del concepto de acceso a la justicia como factor que puede incidir en el progreso económico y por lo tanto en la capacidad de prevenir y superar la pobreza mediante la búsqueda y la utilización de mecanismos innovadores propios de la gestión pública. Por ello, los Estados han y están trabajando en los Objetivos de Desarrollo del Milenio de las Naciones Unidas en materia de justicia que instituye [...] facilitar el acceso a la justicia para todos y crear instituciones eficaces, responsables e inclusivas a todos los niveles. ${ }^{3}$

En el ámbito nacional, nuestro país desde el año 2011 ha sido escenario de una serie de reformas constitucionales que derivaron en cambios estructurales de un nuevo sistema de protección de derechos humanos, así como en materia de competencia económica en búsqueda de procesos eficaces, eficientes, transparentes, de mayor innovación y mejor tecnología, en donde los principales desafíos han sido el asegurar las condiciones mínimas para que las inversiones en las Tecnologías de la Información y las Comunicaciones (TIC) ${ }^{4}$ que constituyen una pieza clave del nuevo paradigma tecnoproductivo, tengan un impacto positivo.

Impacto que deviene del nuevo reparto de responsabilidades que se da entre el Estado y la sociedad en la satisfacción principalmente de los fines públicos. De ahí que se ha dado inicio a una serie de políticas públicas encaminadas al diseño, planeación y regulación sobre la implementación del uso y aplicación de las TIC a las funciones de gobierno, en donde el ejercicio de la función pública de impartir justicia está evolucionando, no solo como una forma de cumplir con requerimientos internacionales, sino como una forma de tutelar el derecho al desarrollo, reconocido como un derecho humano inalienable, a cuyo amparo se ejercita el derecho a la tecnología como parte del derecho de acceso a la justicia en el marco de la justicia digital.

En materia de derechos del contribuyente, en lo que se refiere a la gestión pública el Servicio de Administración Tributaria (SAT) ya está incorporando en sus servicios el uso de las TIC y lo ha ido extendiendo en la tutela del derecho de acceso a la justicia para que el contribuyente pueda promover en línea el recurso de revocación. También el Tribunal Federal de Justicia Fiscal y Administrativa (TFJFA) incluyó el juicio en línea de lo contencioso administrativo.

De igual manera, la Procuraduría de la Defensa de los Derechos del Contribuyente (PRODECON) está siendo innovadora ya que está implementando políticas públicas para que las personas puedan acceder a la justicia en forma gratuita con el uso de las TIC, a través de un acceso que se compone: del conocimiento que las personas deben tener de sus derechos como contribuyentes y de los medios para ejercerlos y hacerlos valer; de la disponibilidad de un servicio eficaz y eficiente de justicia en donde el organismo se constituye como un mecanismo no jurisdiccional de defensa de los contribuyentes, especialmente en el proce-

3 Objetivo No. 16. Resolución de la Asamblea General de la ONU, suscrita por 193 Estados, Nueva York, 25 septiembre del 2015, Transformar nuestro mundo: la Agenda 2030 para el Desarrollo Sostenible, Doc. A/ RES/70/1, de 21.10.2015. En http://www.un.org/sustainabledevelopment/es/. 15 de noviembre del 2015.

${ }^{4}$ Las TIC son el conjunto de herramientas, soportes y canales desarrollados y sustentados por las tecnologías (telecomunicaciones, informática, programas, computadoras e internet) que permiten la adquisición, producción, almacenamiento, tratamiento, comunicación, registro y presentación de informaciones, en forma de voz, imágenes y datos, contenidos en señales de naturaleza acústica, óptica o electromagnética a fin de mejorar la calidad de vida de las personas. ÁVILA DÍAZ, William Darío, Hacia una reflexión histórica de las TIC, 2012, p. 222 -223. http://revistas.usta.edu.co/index.php/hallazgos/article/download/751/1031 
dimiento de quejas o reclamaciones y acuerdos conclusivos, dirigidos en especial para las personas que se encuentran en situación de desventaja y que acuden ante el organismo para ser atendidas.

Motivo por el que en esta investigación, enunciaremos los medios de defensa legales del contribuyente o pagador de impuestos que se han integrado a la justicia digital, y en forma descriptiva y desde la perspectiva del funcionalismo ${ }^{5}$ destacaremos algunos elementos para entender cómo se está tutelando el acceso a la justicia con el uso de las TIC de los contribuyentes, bajo el argumento de que los derechos humanos no solo surten su vigencia en el momento en que se exige al Estado que los garantice investigando, sancionando y reparando su vulneración, sino desde el momento en el que éste efectivamente los garantiza a partir de su respeto y promoción, ya que alcanzar las oportunidades que crea el uso de las TIC en las funciones estatales, dependerá de que se establezcan políticas sólidas y armonizadas para que su implementación se vea como una herramienta clave para la inclusión y el acceso.

\section{LA DEFENSA DE LOS DERECHOS DEL CONTRIBUYENTE}

Para comenzar con la presente investigación, es necesario distinguir tres elementos conceptuales básicos: derechos tributarios, derechos del contribuyente y derechos de los pagadores de impuestos, toda vez que a simple lectura los términos parecen confundirse entre sí, y consideramos que es importante señalar cuáles son sus diferencias.

De acuerdo con Sergio de la Garza el derecho tributario es el conjunto de normas jurídicas que se refieren a los establecimientos de los tributos, esto es, a los impuestos, derechos y contribuciones especiales, a las relaciones jurídicas que se establecen entre la administración $y$ los particulares con motivo de su nacimiento, cumplimiento o incumplimiento, a los procedimientos oficiosos contenciosos que pueden surgir y a las sanciones establecidas por su violación. ${ }^{6}$

Es un derecho que forma parte del sistema fiscal, el cual se refiere a las contribuciones y aportaciones económicas que legalmente los ciudadanos están obligados a efectuar a favor del Estado, [...] es el conjunto de normas jurídicas que reglamentan a la determinación de pago de esas contribuciones que puede válidamente denominarse derecho tributario. ${ }^{7}$ Por tanto, su contenido y alcance se restringe solo a las contribuciones, las cuales forman una parte de los ingresos del Estado cuyo fundamento lo encontramos en el artículo 31, fracción IV de la Constitución Política de los Estados Unidos Mexicanos que estable que es obligación de los mexicanos contribuir al gasto público, tanto de la federación como de las entidades federativas y de los municipios. ${ }^{8}$

En cambio los derechos del contribuyente los podemos definir como las obligacines o los deberes que debe cumplir el Estado a través de su oficina de administración tributaria ante las personas contribuyentes en cuanto a las funciones de recaudación, control y educación

\footnotetext{
5 El funcionalismo es una corriente metodológica que se desarrolla básicamente en la segunda mitad del siglo XX tomando como punto de partida la observación, análisis y estudio de las funciones que realizan las estructuras sociales dentro de la sociedad o en parte de ella. Véase MONTORO VALLESTEROS, Alberto, El funcionalismo en el Derecho, notas sobre N. Luhmann y G. Jakobs, Anuario de Derechos Humanos, Novena época, Vol. 8, 2007. https://revistas.ucm.es/index.php/ANDH/article/viewFile/ANDHo707110365A/20789

6 DE LA GARZA, Sergio, Derecho Financiero Mexicano, México, Porrúa, 2001, p. 26.

7 "Derecho Tributario y su importancia" en Introducción al Derecho Tributario Mexicano, p. 15. http://catarina.udlap.mx/u_dl_a/tales/documentos/ledf/garcia_b_ar/capitulo2.pdf. 23 de marzo del 2015.

8 PONCE GÓMEZ, Francisco, Derecho fiscal, México, Editorial Banca y Comercio, 1994, pp. 66-68.
} 
tributaria, por citar un ejemplo de estos, los contribuyentes tienen el pleno derecho de exigir a la autoridad que les informe el cómo debe pagar sus contribuciones.

Por su universalidad y transversalidad, les pertenecen a todas las personas sin importar la materia o ámbito de aplicación. Son de carácter formal y procedimental. Por tanto, son derechos que deben ser tutelados por el propio Estado y garantizados por la autoridad responsable del servicio público tributario.

Y por último, los derechos de los pagadores de impuestos, que es un término muy utilizado por la Procuraduría de la Defensa del Contribuyente (PRODECON) como una expresión menos técnica para acercar el entendimiento de este derecho a las personas que diariamente se ven involucradas en diversos fenómenos a los que están sometidos principalmente con el pago de los impuestos.

En este término la personalidad del pagador de impuestos es ignorada por el texto legal, aun cuando el legislador debe tomarla en cuenta al establecer el gravamen, pero sin hacer referencia a esta en la ley. ${ }^{9}$

En cuanto a la defensa de los derechos del contribuyente, el Código Fiscal de la Federación, contempla ciertos derechos que el SAT tiene la obligación de tutelar a los contribuyentes, algunos de ellos son:

- Recibir asistencia y orientación gratuita por parte del SAT para poder cumplir con tus obligaciones fiscales; ${ }^{10}$

- Obtener la devolución de saldos a favor de impuestos que procedan; ${ }^{11}$

- Corregir la situación fiscal cuando le sea practicada una auditoría al contribuyente (visita domiciliaria) o una revisión de la contabilidad; ${ }^{12}$

- Que las autoridades fiscales guarden confidencialidad y reserva de los datos y demás información que conozcan los servidores públicos, salvo los casos que autoriza el Código Fiscal de la Federación y otras leyes aplicables. ${ }^{13}$

De igual manera la Ley Federal de los Derechos de los Contribuyentes, ${ }^{14}$ en su artículo $2^{\circ}$ señala entre sus derechos los siguientes:

- Derecho a ser informado o asistido;

- Derecho a ser escuchado;

- Derecho de petición;

- Derecho a la confidencialidad y protección de datos;

\footnotetext{
9 Utilizaremos este término al referirnos al contribuyente, pero muy especialmente cuando lo vinculemos con acciones de la PRODECON.

${ }^{10}$ Artículo 33 del Código Fiscal de la Federación.

${ }^{11}$ Artículo 22 del Código Fiscal de la Federación.

${ }^{12}$ Artículo 27 del Código Fiscal de la Federación.

${ }^{13}$ Artículo 17-H, fracción IX Código Fiscal de la Federación.

${ }^{14}$ Publicada en el Diario Oficial de la Federación el 23 de junio del 2005. 
- Derecho a la autocorrección fiscal;

- Derecho a no pagar más contribuciones de lo debido;

- Derecho a la presunción de buena fe;

- Derecho a una administración ágil y eficiente;

- Derecho a un trato respetuoso; y

- Derecho al acceso de la justicia fiscal.

Actualmente, para que a los contribuyentes que se encuentran en situación de desventaja les sean tutelados sus derechos en forma efectiva y gratuita, está la PRODECON ${ }^{15}$ un organismo público descentralizado, no sectorizado, con personalidad jurídica y patrimonio propio, con autonomía técnica, funcional y de gestión, que tiene el objetivo de proteger, defender y observar los derechos de los contribuyentes.

Asimismo, la PRODECON constituye un mecanismo no jurisdiccional ${ }^{16}$ de defensa de los pagadores de impuestos, especialmente para promover los procedimientos de quejas o reclamaciones y de acuerdos conclusivos. ${ }^{17}$

\section{LA PRODECON COMO OMBUDSMAN DEL CONTRIBUYENTE}

La PRODECON funge como un abogado defensor de los contribuyentes, incluso coloquialmente se hace referencia a este organismo como el ombudsman fiscal, especializado en materia de protección de los derechos del contribuyente o pagador de impuestos, ya que comparte las características de los organismos defensores de los derechos humanos, es decir, es un Defensor no jurisdiccional de derechos, que constituye un instrumento en favor de los gobernados para la protección de los derechos fundamentales, con la particularidad de que se trata de un organismo con nivel de especialización, que se concentra en los derechos de los pagadores de impuestos. ${ }^{18}$

Así, en el ámbito tributario, es un órgano especializado en la protección de los derechos de las personas como contribuyentes, o como lo refiere la propia PRODECON de los derechos de los pagadores de impuestos, los cuales son interdependientes con los demás derechos

\footnotetext{
${ }^{15}$ La creación de este organismo es parte de una serie de reformas en favor de los contribuyentes, cuyos antecedentes se encuentran en la reforma fiscal del 5 de enero del 2004, que incorporó en el Código Fiscal de la Federación el artículo 18-B que establecía su creación. El fundamento legal de su naturaleza jurídica se encuentra en el artículo $2^{\circ}$ de la Ley Orgánica de la Procuraduría de la Defensa del Contribuyente, publicada en el Diario Oficial de la Federación el o4 de septiembre del 2006.

${ }^{16}$ Son los medios de defensa que, sin utilizar la función jurisdiccional, protegen los derechos de los gobernados, mediante procesos propios. Entre ellos se distinguen los recursos administrativos como el recurso de revocación promovido en contra de una resolución de una autoridad fiscal y puede ser a través del buzón tributario; recurso de inconformidad que es un medio de defensa de revisión jerárquica, mediante el cual se pueden defender trabajadores o patrones por un acto emitido por el Instituto Mexicano del Seguro Social.

${ }^{17}$ Estos procedimientos serán descritos en el apartado VI.

18 "Naturaleza de la Procuraduría de la Defensa del Contribuyente como Obudsman (el papel de los defensores no jurisdiccionales de derechos)", en sede de cuadernos de la Procuraduría de la Defensa del Contribuyente, No. XI, México, Procuraduría Federal del Contribuyente, p. 37.
} 
humanos ya que no puede pensarse en una efectiva protección de éstos sino se garantiza su tutela plena.

Tutela que se observa en el desempeño de la tarea fundamental de salvaguardar los derechos humanos, que van más allá de las disposiciones legales, debido a las facultades que tiene en materia de investigación, esto es, para realizar estudios, análisis e identificación de problemas que derivan de la estructura del sistema tributario, que podrían tener como consecuencia la vulneración de los derechos del contribuyente. Problemas que, incluso, pueden ser de la propia normatividad de la materia. Lo que implica que, aun cuando las relaciones entre el Estado y los contribuyentes se estén dando dentro del marco legal, puede haber prácticas irregulares innecesariamente onerosas que están afectando negativamente los derechos del contribuyente.

Por esto, la PRODECON, no se queda en lo estrictamente legal, sino que está obligada a defender los derechos de los pagadores de impuestos, aún más allá del texto legal, buscando siempre la equidad y la justicia. ${ }^{19}$

Además, sus facultades de investigación son amplias en cuanto a que no actúa sólo por el impulso de las partes, sino también de oficio. Tiene que ser proactiva en la defensa de los derechos de los contribuyentes. Si bien es cierto que la orientación, investigación de quejas o reclamaciones, las conciliaciones o acuerdos, y la representación y defensa legal son elementos esenciales y cotidianos que inician cuando una persona acude ante el organismo para ser atendida, también lo es, que la labor no se agota ahí, ya que tiene la obligación de desenvolverse de oficio adelantándose a los problemas para proponer medidas efectivas de solución ante problemas recurrentes. ${ }^{20}$

Es importante aclarar, que la procuraduría no sustituye a las instituciones de defensa legal existentes, sino que complementa los medios de defensa legales, ya que persigue la mejora del funcionamiento de la impartición de justicia en materia tributaria. ${ }^{21}$

Así mismo, al tutelar el derecho de acceso a la justicia, realiza actividades de promoción y difusión, pues están dentro de sus facultades el difundir la cultura contributiva realizando campañas de comunicación y difusión social respecto de los derechos y garantías de los contribuyentes, proponiendo mecanismos que alienten a éstos a cumplir voluntariamente con sus obligaciones. ${ }^{22}$

Incluso está facultada para promover el estudio, la enseñanza y la divulgación de las disposiciones fiscales, particularmente las relativas a garantías, elementos del acto administrativo, facultades de las autoridades competentes, procedimientos y medios de defensa al alcance del contribuyente. ${ }^{23}$ Elemento importante, pues como autoridad cumple garantizando el derecho de acceso al conocimiento que las personas deben tener sobre sus derechos y obligaciones como pagadores de impuestos, así como de los medios para hacerlos valer.

También como órgano defensor, tiene el deber de difundir la información y actuar como intermediario para enfrentar y detener las arbitrariedades de las autoridades fiscales de la federación y como todas las autoridades que responden al mandato constitucional, tiene la

\footnotetext{
${ }^{19}$ Desde su creación ha buscado y procurado una defensa eficaz y a la fecha se han promovido un total de seis mil 269 medios de defensa en todo el país, con un porcentaje de resoluciones favorables de alrededor del $70 \%$.

${ }^{20}$ Artículo $5^{\circ}$, fracción XI, de la Ley Orgánica de la Procuraduría Federal del Contribuyente.

${ }^{21}$ SERRANO ANTON, Fernando, El régimen jurídico de la defensa del contribuyente del Ayuntamiento de Madrid: Hacia una administración orientada al servicio del contribuyente, España-México, Fontamara, 2013, p. 86-87.

${ }^{22}$ Artículo $5^{\circ}$, fracción XV de la Ley Orgánica de la Procuraduría Federal del Contribuyente.

${ }^{23}$ Artículo 5ㅇ fracción V de la Ley Orgánica de la Procuraduría Federal del Contribuyente. 
obligación de promover, respetar, proteger y garantizar los derechos humanos de conformidad con los principios consagrados en el artículo $1^{\circ}$ de la Constitución Política y como defensor de los contribuyentes es un instrumento idóneo y fundamental para lograr una mayor transparencia y calidad en la prestación del servicio tributario, y para alcanzar el anhelado equilibrio en las relaciones entre el contribuyente y la administración. ${ }^{24}$

Relación en la que Numerosos contribuyentes, por tanto, podían quedar fácilmente sin acceso a la justicia fiscal, por carecer de los recursos económicos necesarios para ello, ante una gran variedad de actos que emiten las autoridades fiscales, como negativas de devolución, adeudos fiscales, procedimientos de ejecución y multas. ${ }^{25}$

Por ello, la PRODECON se suma como un organismo garante más dentro del sistema mexicano de protección de los derechos fundamentales, pues de manera colateral puede actuar con la Comisión Nacional de los Derechos Humanos, y las comisiones estatales de los derechos humanos, así como desde luego con los órganos jurisdiccionales con competencia en la materia. ${ }^{26}$

\section{EL DERECHO DE ACCESO A LA JUSTICIA CON LA IMPLEMENTACIÓN DEL USO DE LAS TIC}

El acceso a la justicia puede concebirse como la posibilidad de que las personas puedan llevar sus conflictos ante los órganos encargados de impartir justicia y obtener respuestas que contribuyan a solucionar sus problemas en lo particular y los problemas sociales en lo general. ${ }^{27}$

En su conceptualización integra a un conjunto de instituciones, principios procesales y garantías jurídicas, así como directrices político-sociales, en cuya virtud el Estado debe ofrecer y realizar la tutela [...] de los derechos de los justiciables, en las mejores condiciones posibles de acceso económico y de inteligibilidad cultural, de modo tal que dicha tutela no resulte retórica, sino práctica. ${ }^{28}$

De ahí que, el acceso a la justicia como servicio público ofrecido por el Estado desenvuelva su organización con criterios de eficiencia, eficacia, transparencia y legalidad, que además hoy supone un servicio que debe ser moderno, pues en esta época la tecnología está en continuo avance y no se le puede ignorar debido a su gran utilidad. De hecho, las personas usuarias de este servicio, ya no toleran que en los órganos encargados de impartir justicia no les brinden un servicio de carácter tecnológico y que deban ir recabando información de oficina en oficina, o ir buscando sus expedientes entre una montaña de papeles, entre otras situaciones.

Por ello, el Estado está aprovechando los beneficios que le aporta la tecnología, mejorando sus procesos de gestión, adaptando sus estándares de funcionamiento y transformándose paulatinamente como parte de las exigencias no solo económicas y sociales, sino también

\footnotetext{
${ }^{24}$ SERRANO ANTÓN, Fernando, Op. Cit., nota no. 21, p. 133.

${ }^{25}$ LADRÓN DE GUEVARA, Diana Bernal, Discurso Foro Criterios Jurisdiccionales: La labor de la Procuraduría de la Defensa del Contribuyente como abogado defensor, agosto del 2014. http://www.prodecon. gob.mx/index.php/home/sala-de-prensa/comunicacion-social/boletines/2014/166-boletines-de-prensanacional/2014/8agosto/1223-boletin-nacional-42-2014

26 "Naturaleza de la Procuraduría de la Defensa del Contribuyente como Ombudsman", op. cit., nota no. 18.

${ }^{27}$ CAPELLETTI y GARTH, 1978 en Libro Blanco de la Reforma Judicial: Una agenda para la Justicia de México, México, Suprema Corte de Justicia-Poder Judicial, 2006.

${ }^{28}$ PETRACHI, Enrique, "Acceso a la justicia”, en La Ley, 27 de mayo de 2004.
} 
derivado de los compromisos internacionales ${ }^{29}$ que México ha ido asumiendo desde 1986 con la Declaración sobre el Derecho al Desarrollo, en materia del progreso científico y el uso y la implementación de las Tecnologías de la Información y las Comunicaciones en un contexto de una economía mundial basada en la información y el conocimiento, hasta los Objetivos de Desarrollo Sostenible del Nuevo Milenio 2015-2030 suscritos en 2015, con el cambio en el entendimiento del concepto de acceso a la justicia como un factor que puede incidir en la capacidad que tienen los Estados para prevenir y superar la pobreza mediante la búsqueda y la utilización de mecanismos innovadores.

Motivo por el que el derecho de acceso a la justicia con la implementación de las TIC además de ser un servicio público, tiene que entenderse como un derecho humano que al ser debidamente tutelado traerá consigo beneficios económicos. Por esto es importante mencionar que los Estados al implementar el uso de las TIC en las políticas públicas, deben tomar en cuenta, además de la innovación en la gestión y los procesos para hacerla eficaz, eficiente, responsable y transparente, que sea inclusiva, es decir, que deben considerar los obstáculos que continúan imperando en el acceso a la justicia como:

a) La pobreza y las limitaciones económicas para acceder a una defensa adecuada;

b) El acceso a la justicia digital y las limitaciones en la utilización de sus herramientas derivado de las deficiencias educativas, así como el no saber utilizar la información;

c) Ausencia de confianza en las instituciones, debido a la nula o la poca atención por parte de las autoridades, así como la falta de información o de resultados efectivos;

d) Desconocimiento por parte de las personas en cuanto a sus derechos y la forma como éstos deben ser tutelados por el Estado;

e) Procesos complicados y retardados que ocasionan daños económicos adicionales;

f) Carga de trabajo de las instituciones, entre otros. ${ }^{30}$

Obstáculos que al día de hoy generan una brecha digital, y hacen necesario que las autoridades responsables de planear e implementar las políticas institucionales consideren esta realidad, ya que exige enormes responsabilidades relacionadas con el derecho de acceder a las TIC en condiciones de equidad, para impulsar la eficiencia de la economía y la producción de certeza en una sociedad que cada día es más compleja.

Razón por la que creemos que la implementación del uso de las TIC en cualquier procedimiento dirigido por un órgano encargado de impartir justicia, ya no debe estar basada en

\footnotetext{
${ }^{29}$ Entre ellas podemos mencionar la Resolución 41/128 de la Organización de las Naciones Unidas en la que se adoptó la Declaración sobre el Derecho al Desarrollo 1986; el Informe 2000, A/55/3 sobre desarrollo y cooperación internacional en el siglo XXI: la función de la tecnología de la información en el contexto de una economía mundial basada en el saber; la Cumbre del Milenio de las Naciones Unidas 200o; la Cumbre Mundial sobre la Sociedad de la Información 2003; la Comisión Económica para la América Latina (CEPAL) y el Plan de Acción sobre la Sociedad de la Información en América Latina (eLAC) 2007; la Cumbre Judicial Iberoamericana, que elaboró el proyecto "e-justicia: la Justicia en la Sociedad del Conocimiento.

${ }^{30}$ Mas sobre los problemas y los obstáculos para acceder a la justicia MARANIELLO, Patricio Alejandro, "las limitaciones económicas al acceso a la justicia", en IUS Revista del Instituto de Ciencias Jurídicas de Puebla A.C., No. 21, 2008, p. 107.
} 
meros planes de modernización, sino como parte de la evolución de un derecho humano con un contenido prestacional cuyo desarrollo está sujeto a los principios de universalidad, progresividad, no discriminación y no regresión, que asegure las condiciones económicas y sociales que permitan su tutela efectiva.

Máxime, si lo relacionamos con el derecho fundamental previsto en el artículo 6, párrafo tercero de la Constitución Política que señala: El Estado garantizará el derecho de acceso a las tecnologías de la información y comunicación, así como los servicios de [...]telecomunicaciones incluido el de banda ancha e internet.

Por tanto, el Estado debe asegurar que todas las personas tengan libre y fácil acceso a las TIC, ya que se establece como una potestad el utilizarlas, y nos referimos a esto, pues el problema que se pudiera generar o que ya se está generando, sería que por el uso de las TIC en los servicios públicos como la administración de justicia una persona o cierto grupo de personas no tuviera acceso a éste, o bien, no tuviese el conocimiento para hacer uso del mismo, en ese supuesto se estaría obstaculizando el derecho de acceso a la justicia y como consecuencia de ello habría denegación de la misma, y México se comprometió a eliminar los obstáculos y a adoptar las medidas legislativas, económicas y técnicas, en lo individual y mediante la asistencia y la cooperación internacionales, hasta el máximo de los recursos de que disponga.

\section{EL USO DE LAS TIC EN MATERIA TRIBUTARIA}

Para comenzar con este apartado, es necesario describir brevemente la evolución, principalmente de los servicios públicos orientados a la atención de los contribuyentes y enseguida hacer mención de los avances en el acceso a la justicia a través del juicio en línea que se desahoga ante el Tribunal Federal de Justicia Fiscal y Administrativa (TFJFA), ya que la implementación del uso de las TIC significa para los contribuyentes que los sistemas en la administración tributaria deben ser capaces de monitorear permanentemente los riesgos fiscales, detectar inconsistencias, verificar la congruencia de los datos proporcionados a la autoridad y tener el de control de los mismos, y cuando esto no funcione y llegue a vulnerar los derechos, sea posible tener acceso a la justicia con el uso de la tecnología. ${ }^{31}$

En el ámbito de la gestión pública, la administración tributaria ha desarrollado servicios soportados en medios tecnológicos cuyas características han ido incorporando facilidades resultantes tanto de la disponibilidad de nuevas tecnologías, como de la mejora en cuanto a calidad de información disponible.

En este sentido, estos servicios han progresado y se han hecho disponibles en internet con información presentada a los contribuyentes a través de enlaces estructurados en opciones de menús. Los contenidos de información para su difusión, fueron inicialmente los mismos con los que se preparaban cartillas, folletos e instructivos impresos que se distribuían tanto a los contribuyentes cuando visitaban las oficinas de la administración tributaria como a los colaboradores que trabajaban en la plataforma de atención.

Posteriormente el servicio público de administración tributaria inició una etapa en la que incorporó facilidades de búsqueda y actualización de documentos con el propósito general de prestar servicios, generalmente fuera de línea, complementados con el envío de archivos. Después los servicios y soluciones brindadas de manera electrónica fueron evolucionando

\footnotetext{
${ }^{31}$ ZAMBRANO, Raúl, "Uso de las TIC en materia de asistencia al contribuyente", en Revista de Administración Tributaria, CIAT/AEAT/IEF, No. 35, junio de 2013.
} 
hasta incluir transacciones ejecutadas directamente sobre el sitio de la administración en internet.

Actualmente, el mayor nivel de desarrollo, se centra específicamente en servicios integrados prestados sobre diferentes plataformas y en los que se pueden identificar tres elementos importantes:

1. Un soporte multiplataforma para desarrollar los trámites;

2. Un único punto de entrada para los diferentes trámites y puntos de gestión, acompañados por una interfaz común de gestión; e

3. Interoperabilidad, en que los sistemas y aplicaciones de diversas partes de la administración cooperen para intercambiar información y agilizar trámites en beneficio de la prestación de servicios de mejor calidad mientras al mismo tiempo incrementan sustancialmente la capacidad de control del cumplimiento.

Así mismo, las principales transformaciones son:

1. Complejidad de transacciones;

2. Manejo y estabilidad de problemas;

3. Aspectos de seguridad; $y$

4. Acuerdos de nivel de servicio, entre otros.

Toda vez que, el uso de la tecnología y los formatos estandarizados forman parte de la automatización de trámites. Abriendo un paréntesis, como se verá más adelante, a través de un formato en línea podemos comenzar con la promoción de una queja o reclamación en la PRODECON, ya que esta automatización facilita las tareas de fiscalización y la detección de irregularidades en los procesos de cumplimiento por parte de los contribuyentes de manera más oportuna y a menor costo.

Así las actividades de asistencia a los contribuyentes están orientadas a facilitar el cumplimiento, y por esto presentan algunas características que responden propiamente a las demandas de estos servicios como es la ampliación de las capacidades de entendimiento con prestaciones cada vez más complejas, pero con interfaces sencillas, en donde se espera poder accesar a determinados servicios desde la computadora, la tableta, el celular inteligente, etc., en los que seguramente sus actuaciones, sus claves, sus registros se sincronicen.

En cuanto a los avances en el ámbito del acceso a la justicia, encontramos que el juicio en línea es una realidad en el Tribunal Federal de Justicia Fiscal y Administrativa, aún, cuando solo desahoga el juicio de nulidad o también llamado juicio contencioso administrativo federal y el recurso de revocación en línea. Fuera de estos procedimientos legales, los demás sólo son recurribles por la vía tradicional u ordinaria, así como los servicios que en la tutela del derecho de acceso a la justicia está implementando PRODECON.

A continuación, ofrecemos una descripción de los procedimientos en línea que se desahogan en el SAT y en el TFJFA. 


\section{V.1. JUICIO EN LINEA CONTENCIOSO ADMINISTRATIVO FEDERAL}

En el ámbito Contencioso Administrativo, la Ley Federal del Procedimiento Contencioso Administrativo (LFPCA) en su capítulo X, titulado Del Juicio en Línea ${ }^{32}$ crea un verdadero procedimiento jurisdiccional en forma electrónica administrado por el Tribunal Federal de Justicia Administrativa.

La citada ley en su artículo 1-A fracción XIII, dispone que por Juicio en Línea se entenderá la substanciación y resolución del juicio contencioso administrativo federal en todas sus etapas, así como de los procedimientos previstos en el artículo 58 de esta Ley, a través del Sistema de Justicia en Línea, incluso en los casos en que sea procedente la vía sumaria. Cabe mencionar que el 21 de octubre del 2011, se emitió la primera sentencia de un juicio sumario, en la que el procedimiento tardó en resolverse 31 días.

Este dato nos indica que una de los principales objetivos que se pretende conseguir con la implementación del uso de las TIC en la impartición de justicia es la prontitud tal y como lo consagra la Constitución Política en el artículo 17.

Además, el juicio en línea presenta cualidades adicionales como son:

- $\quad$ El sistema será en idioma español;

- $\quad$ El uso del sistema es gratuito; $y$

- $\quad$ Por seguridad el acceso al sistema requiere Firma Electrónica Avanzada (FIEL);

En esta materia, es importante aclarar que la Ley del Servicio de Administración Tributaria, no hace referencia al juicio en línea, pero está implícito que es un derecho del contribuyente o pagador de impuestos optar por promover el juicio en línea directamente ante TFJFA, por lo que podrá hacerlo en términos de los artículos $58 \mathrm{~A}$ al $58 \mathrm{~S}$, mismo que describiremos a continuación:

En la descripción del cómo comenzar el juicio en línea, el sistema solicita que se atiendan los siguientes requisitos:

- Acudir a un módulo del TFJFA y obtener una Clave de Acceso y Contraseña;

- Obtener la Firma Electrónica Avanzada en los módulos del SAT; e

- Ingresar a la página https://www.juicioenlinea.gob.mx e ingresar la Clave de Acceso y Contraseña.

Y una vez que se han integrado, la forma como se desahoga el procedimiento es la siguiente:

1. Se promoverá dicho juicio a través del Sistema de Justicia en Línea.

2. Demandante ejercerá su derecho a presentar su demanda en línea a través del Sistema de Justicia en Línea del Tribunal, las autoridades demandadas deberán comparecer y tramitar el juicio

\footnotetext{
${ }^{32}$ Adición publicada en el Diario Oficial de la Federación, el 12 de junio del 2009.
} 
en la misma vía, señalando su correo electrónico para poder seguirlo, sino lo señalaré el juicio se tramitará por la vía ordinaria.

3. El demandado, al contestar tendrá derecho a ejercer su opción para que el juicio se tramite y resuelva en línea, señalando para ello su domicilio y dirección de correo electrónico. A fin de emplazar al demandado, el Secretario de Acuerdos que corresponda, imprimirá y certificará la demanda y sus anexos que se notificarán de manera personal, en caso de que el demandado rechace que sea en línea.

4. En el sistema integrará el expediente electrónico, mismo que incluirá todas las promociones, pruebas y otros anexos que presenten las partes, oficios, acuerdos, y resoluciones tanto interlocutorias como definitivas, así como las demás actuaciones que deriven de la substanciación del juicio en línea, garantizando su seguridad, inalterabilidad, autenticidad, integridad y durabilidad, conforme a los lineamientos que expida el Tribunal. En los juicios en línea, la autoridad requerida, desahogará las pruebas testimoniales utilizando el método de videoconferencia, cuando ello sea posible.

5. El registro de la FIEL, clave de acceso y contraseña, implica el consentimiento expreso de que dicho sistema registrará la fecha y hora en la que se abran los archivos electrónicos, que contengan las constancias que integran el expediente electrónico, para los efectos legales establecidos en este ordenamiento.

6. Una vez recibida por vía electrónica cualquier promoción de las partes, el sistema emitirá el acuse de recibo electrónico correspondiente, señalando la fecha y la hora de recibido.

7. Actuaciones hechas, serán validadas con la firma electrónica avanzada de los Magistrados y Secretarios de Acuerdos que den fe según corresponda.

8. Los documentos que las partes ofrezcan como prueba, incluido el expediente administrativo a que se refiere el artículo 14, fracción V, de la LFPCA, deberán exhibirlos de forma legible a través del Sistema de Justicia en Línea del Tribunal.

Tratándose de documentos digitales, se deberá manifestar la naturaleza de los mismos, especificando si la reproducción digital corresponde a una copia simple, una copia certificada o al original y tratándose de esta última, si tiene o no firma autógrafa.

Las pruebas documentales que ofrezcan y exhiban las partes tendrán el mismo valor probatorio que su constancia física.

9. Para el caso de pruebas diversas a las documentales, los instrumentos en los que se haga constar la existencia de dichas pruebas se integrarán al expediente electrónico. El Secretario de Acuerdos a cuya mesa corresponda el asunto, deberá digitalizar las constancias relativas y procederá a la certificación de su cotejo con los originales físicos, así como a garantizar el resguardo de los originales $\mathrm{y}$ de los bienes materiales que en su caso hubieren sido objeto de prueba.

Para el caso de pruebas diversas a las documentales, éstas deberán ofrecerse en la demanda y ser presentadas a la Sala que esté conociendo del asunto, en la misma fecha en la que se registre en el 
sistema la promoción correspondiente a su ofrecimiento, haciendo constar su recepción por vía electrónica.

10. Las partes exhibirán copias para correr los traslados que la Ley establece, sólo cuando hubiese tercero interesado, en cuyo caso, a fin de correrle traslado, el demandante deberá presentar la copia de traslado con sus respectivos anexos. En el escrito a través del cual el tercero interesado se apersone en juicio, deberá precisar si desea que el juicio se continúe substanciando en línea y señalar en tal caso, su dirección de correo electrónico.

\section{Notificaciones:}

- Todas las actuaciones y resoluciones que conforme a las disposiciones de la LFPCA deben notificarse en forma personal, mediante correo certificado con acuse de recibo, o por oficio, se deberán realizar a través del Sistema de Justicia en Línea del Tribunal.

- El actuario deberá elaborar la minuta electrónica en la que precise la actuación o resolución a notificar, así como los documentos que se adjunten a la misma. Dicha minuta, que contendrá la firma electrónica del actuario, será ingresada al sistema junto con la actuación o resolución respectiva y los documentos adjuntos.

- El actuario enviará a la dirección de correo electrónico de la o las partes a notificar, un aviso informándole que se ha dictado una actuación o resolución en el expediente electrónico.

- El sistema registrará la fecha y hora en que se efectúe el envío.

- Se tendrá como legalmente practicada la notificación, cuando el sistema genere el acuse de recibo electrónico donde conste la fecha y hora en que la o las partes notificadas ingresaron al expediente electrónico, lo que deberá suceder dentro del plazo de tres días hábiles siguientes a la fecha de envío del aviso al correo electrónico de la o las partes a notificar.

- En caso de que, en el plazo señalado el sistema no genere el acuse de recibo donde conste que la notificación fue realizada, la misma se efectuará mediante lista y por Boletín Procesal al cuarto día hábil contado a partir de la fecha de envío del correo electrónico.

Como se aprecia, el ejercicio de impartir justicia se está transformando y comienza a ser realidad la tutela del derecho humanos al desarrollo y su ejercicio mediante el derecho a la tecnología como parte del derecho de acceso a la justicia en el marco de la justicia digital, así como el cumplimiento de elementos que integran el objetivo de justicia de los Objetivos de Desarrollo Sostenible 2015-2030, como el crear instituciones eficaces y responsables.

En cuanto a la eficacia, definitivamente hay una celeridad debido a la reducción notable en el tiempo para el desarrollo del juicio, ya que al ser hábiles las 24 horas del día y el acceso al sistema los 365 días del año; se garantiza la participación de tiempo completo a las personas involucradas, lo que representa, por ejemplo, que desahogar un juicio sumario en línea tome un promedio de 70 días (y no de 3 años que es lo que dura aproximadamente el juicio 
tradicional); también permite agilizar los trámites realizados por las partes en un juicio, así como registrar, controlar, procesar, almacenar, difundir, transmitir, administrar y notificar todo el procedimiento. ${ }^{33}$

Otros beneficios que se observan son los ecológicos y económicos, ya que se evita el gasto excesivo del papel al constar todo en medios digitales; y el hecho de que las notificaciones sean por correo electrónico permite que se reduzca el tiempo en trámites, traslados y gastos en combustibles.

Un elemento que nos atrevemos a criticar en cuanto a la continuidad del desarrollo del procedimiento en línea en una siguiente instancia, es que, si el contribuyente o pagador de impuestos desea interponer el recurso de revisión fiscal contra los actos o resoluciones derivadas del juicio en línea, el mecanismo por la vía electrónica se interrumpe, y en esos casos, el personal de la Sala o Tribunal correspondiente debe imprimir el expediente electrónico y certificar las constancias del juicio que se trate.

En materia de amparo, no hay coordinación o interdependencia entre el ámbito contencioso administrativo y el juicio de amparo, por lo que el juicio en línea también se interrumpe, y la regla general es que se debe de imprimir todo lo actuado en el juicio previo y, solo cuando expresamente el juzgado de distrito o tribunal colegiado solicite que se le remita la información en medios electrónicos, podrá remitirse el expediente en línea.

De igual manera quedan pendientes otros elementos que permitan la materialización plena del objetivo de justicia de los objetivo de desarrollo sostenible, como el acceso a la justicia inclusiva, ya que continua presente la limitación para cualquier persona para acceder a una defensa adecuada por la vía digital, además, es complicado realizar el registro de usuario del sistema, ya que se requiere hacer todo un trámite en las oficinas de las salas regionales del Tribunal, lo que requiere dedicar tiempo y gastos adicionales pues no en todos los Estados de la república hay salas regionales.

Otro obstáculo que se suma es el de la edad, hay una brecha generacional entre los abogados que actualmente litigan y los estudiantes de derecho, en donde para los primeros se observa resistencia a la utilización de nuevas tecnologías, derivado de la desconfianza que tienen en el uso de internet para desahogar los procedimientos, el temor de perder los asuntos por no llevar de manera correcta la técnica en línea, etc., prefiriendo el juicio tradicional y los expedientes en papel; en cambio para los segundos, que ya se identifican con las TIC, ya no conciben el desarrollo del procedimiento de otra manera. Por lo que eliminar ese obstáculo tomará tiempo. ${ }^{34}$

Según datos, veintiún meses después de entrar en vigor los juicios en línea se desahogaron 1,997 demandas de un aproximado de 200 mil que ascienden en todo el año, lo que representa solo el 2 por ciento de los asuntos en todo el país. De igual manera en 2014, el TFJFA atendió un total de 164,785 demandas, de las cuales, 110,307 (66.9\%) correspondieron a demandas nuevas presentadas, de las que 101,335 (91.9\%) fueron procedentes, y solo 1,318

33 Consultado en: https://www.juicioenlinea.gob.mx/portalexterno/faces/pages/seguridad/login2.jspx?_afrLoop=1079946248579391\&_afrWindowMode=o\&_adf.ctrl-state=17ewdmtieo_4

${ }^{34}$ MENDEZ, Alfredo, "Fracaso' el sistema de juicio en línea del tribunal fiscal, entrevista al Mtro. Jesús Alberto Guerra Rojas", en La jornada, 13 de mayo de 2013, p. 8. http://www.jornada.unam.mx/2013/05/13/ politica/oo8nipol. 20 de marzo de 2014. 
se desahogaron en línea, 913 fueron para la vía ordinaria (69.3\%) y 405 para la vía sumaria $(30.7 \%) .35$

Con esta información, se evidencia que el juicio en línea no está al alcance de cualquier persona, y la tutela del derecho al acceso a la justicia con el uso de las TIC queda incompleta, pues las herramientas para utilizarlo hacen que sea necesario que un abogado lo desahogue y queda de manifiesto que se incrementa la desigualdad entre quienes tienen recursos económicos para contratarlo de quienes no los tienen, destacándose la desigualdad económica y por ende la condición social.

Es necesario que el Estado realice un esfuerzo extra para que el derecho de acceso a la justicia a través del juicio en línea permita incrementar el acceso a cualquier persona, tomando en cuenta que este derecho debe ser alcanzable para todos con independencia de las circunstancias personales, medios económicos o conocimientos; un proceso que resulte ágil y sencillo para poder afirmar que ahora sí quedo en el pasado lo que para algunas personas implica el derecho de acceder a la justicia, es decir, la reducida posibilidad de acceder al servicio público con la asistencia de un abogado o representante legal.

\section{V.2. RECURSO DE REVOCACIÓN EN LÍNEA}

Las autoridades fiscales al recaudar contribuciones de las personas físicas y morales, cuando consideran necesario reclamarlas actúan en forma represiva y aun cuando adviertan un error no se detienen en su actividad, es por ello, que los contribuyentes o pagadores de impuestos pueden optar por promover el recurso de revocación siempre y cuando haya un error por parte de las autoridades, no quieran regresar alguna contribución mal empleada o estén aplicando mal sus reglas.

El procedimiento se desahoga ante el SAT y a pesar de ser optativo (el contribuyente puede preferir por impugnar un acto mediante dicho recurso o bien promover su acción mediante juicio ante el TFJFA el cual ofrece una serie de derechos y beneficios como: garantizar el interés fiscal por el tiempo que dure la tramitación del recurso; ${ }^{36}$ exhibir todas las pruebas que por omisión u olvido no se hayan aportado en el procedimiento fiscalizador (considerando que lo no exhibido en el recurso, no se podrá exhibir en el juicio contencioso administrativo).

Respecto a su desarrollo en línea, encontramos su fundamento en los artículos 18, 19, 116, $117,121,122,123,125,126,127,128,130,131,132$ y 133 del Código Fiscal de la Federación; el artículo 203 de la Ley Aduanera; y la regla 2.18.1 de la Resolución Miscelánea Fiscal. En el que el uso de las TIC desempeñan un papel destacado, ya que en el portal del SAT37 proporciona información suficiente para acceder y conocer la información para saber cómo promoverlo y que se necesita para hacerlo.

El recurso de revocación en línea puede ser presentado por cualquier persona física o moral a través del Buzón Tributario, ${ }^{38}$ por regla general es dentro de los 30 días siguientes a aquél en que haya surtido efectos la notificación de la resolución o acto que impugna el

\footnotetext{
${ }^{35}$ Informe de resultados de la fiscalización superior de la cuenta pública 2014 y Sistema de Control y Seguimiento de Juicios del 28 de octubre y del 5 de noviembre de 2015, pp. 3 y 4 . Consultado en: http://informe.asf. gob.mx/Documentos/Auditorias/2014_0036_a.pdf

${ }^{36}$ Artículo 144, segundo párrafo del Código Fiscal de la Federación.

37 https://www.sat.gob.mx/informacion_fiscal/tramites/declaraciones_pagos_garantias/Paginas/ficha_192_ cff.aspx

${ }^{38}$ https://www.siat.sat.gob.mx/PTSC/
} 
contribuyente, pero si se trata de violaciones al procedimiento administrativo de ejecución, entonces el término es dentro de los 10 días siguientes a la fecha de publicación de la convocatoria de remate, o bien en cualquier tiempo, cuando un tercero afirme ser propietario de los bienes o negociaciones o titular de los derechos embargados.

Entre los requisitos que se solicitan y que están descritos en el portal del SAT, son:

- Escrito de promoción.

- Resolución o acto impugnado.

- Constancia de notificación del acto impugnado.

- Pruebas.

- Escrito de anuncio de pruebas adicionales.

- Escrito de exhibición de pruebas adicionales.

- Documentación relacionada con el recurso de revocación.

El procedimiento para presentarlo en línea es el siguiente:

- se ingresa a la sección trámites y se selecciona la opción buzón tributario;

- se captura el RFC y la contraseña o e.firma, seguido del inicio de sesión;

- se llenan los datos solicitados por el formulario electrónico, indicando el trámite que se desea realizar;

- se ingresan el archivo(s) comprimidos en (.zip) que se generaron en el equipo de cómputo, USB o CD;

- se envía el trámite al SAT y se imprime el acuse de recibo electrónico;

- se espera respuesta del SAT a través del correo electrónico que se registró al contactarse.

Como ya lo expresamos, los usos de las TIC juegan un papel importante para hacer valer un derecho de defensa como contribuyente o pagador de impuestos contra un acto de carácter fiscal a través de este recurso. Su trámite optimiza la gestión, mejorando el funcionamiento en la impartición de justicia tanto en el área operacional como en la institucional, por ende, se brinda un servicio más moderno que implica la sistematización del procedi- 
miento, la desaparición del uso de papel, el ahorro del tiempo y los gastos que se generaban en el procedimiento ordinario.

Sin embargo, la desventaja es que a partir del 2017 si una persona no cuenta con su Buzón Tributario no podrá hacer valer el recurso de revocación,39 de igual manera si resulta afectado por un acto o resolución hacendaria. ${ }^{40} \mathrm{Y}$ al volverse un derecho exclusivo a un procedimiento en línea, el Estado está negando el derecho a acceder a un remedio que antes podía ejercerse libremente, lo que representa una vulneración al derecho de acceso a la justicia (aun cuando el agotar este medio de defensa sea optativo antes de promover el juicio contencioso administrativo por las ventajas que ya hemos mencionado al inicio de este apartado).

Consideramos que es así, porque el Estado al implementar las políticas públicas, además de la innovación en la gestión y los procesos para hacerlas eficaces y eficientes, debe tomar en cuenta la inclusión, es decir, que en su implementación debe entenderse que la forma en que actualmente se accede a la justicia es a partir de un contexto de desigualdad social, pobreza, desconfianza, deficiencias educativas, falta de información, etc., elementos que conforman la realidad y que generan los obstáculos de la denominada brecha digital.

Y se adiciona un obstáculo más, ya que para promover el recurso de revocación en línea se requiere que el contribuyente cumpla con una gran cantidad de especificaciones técnicas para accesar, haciendo indispensable que un experto en temas informáticos le auxilie, pues el trámite resulta complejo, lento y poco práctico.

Lo ideal sería que se continuara el derecho de interponer el recurso por la vía tradicional, y al mismo tiempo por la vía electrónica para aquellos contribuyentes que cuenten con los medios para hacerlo, (como sucede con el juicio en línea contencioso administrativo), porque la inexistencia de un sistema accesible para hacer valer el derecho de defensa como contribuyente o pagador de impuestos contra un acto de carácter fiscal constituye una transgresión al derecho de acceso a la justicia por parte del Estado.

Por tanto, creemos que la implementación del uso de las TIC en cualquier procedimiento dirigido por un órgano encargado de impartir justicia, debe introducirse paulatinamente, y no basarse en planes de modernización, como parte de la evolución de un derecho humano con un contenido prestacional cuyo desarrollo está sujeto a los principios de universalidad, progresividad, no discriminación y no regresión, que asegure las condiciones económicas y sociales que permitan una tutela efectiva para todos.

VI. EL DERECHO DE ACCESO A LA JUSTICIA CON LA IMPLEMENTACIÓN DEL USO DE LAS TIC EN LA PRODECON

Como ya lo hemos mencionado, el reparto de responsabilidades que actualmente se da entre el Estado y la sociedad en la satisfacción principalmente de los fines públicos, ha provocado que se dé inicio a una serie de políticas públicas encaminadas al diseño, planeación y regulación sobre la implementación del uso y aplicación de las TIC a las funciones de gobierno, en donde el ejercicio de la función pública de impartir justicia está evolucionando para

\footnotetext{
${ }^{39}$ Con la finalidad de otorgar certeza jurídica a los contribuyentes, la PRODECON y el SAT concertaron que las resoluciones en las que será obligatorio la interposición del recurso de revocación en línea a que se refiere el artículo 121 del Código Fiscal de la Federación, serán aquellas cuya notificación surta efectos a partir del 4 de enero del 2017, y no para los ejercicios anteriores. Más información en: https://www.gob.mx/prodecon/ articulos/prodecon-informa-recurso-de-revocacion-en-linea?idiom=es

${ }^{40}$ Su única vía para ejercer su derecho de defensa será el juicio contencioso administrativo ante la Sala Fiscal Competente.
} 
brindarse a las personas, no solo para cumplir con los requerimientos internacionales, sino como una forma de tutelar el derecho al desarrollo, reconocido como un derecho humano inalienable, a cuyo amparo se ejercita el derecho a la tecnología como parte del derecho de acceso a la justicia en el marco de la justicia digital.

Justicia digital que se está extendiendo a la justicia fiscal que debe ser garantizada por el Estado, lo que implica que el contribuyente o pagador de impuestos contará con los medios que le permitan ejercer y defender sus derechos y obligaciones tributarias. De ahí que la PRODECON dentro de sus políticas esta implementado acciones para que los contribuyentes o pagadores de impuestos puedan acceder a la justicia con el uso de las TIC.

Un acceso que se compone del conocimiento que las personas deben tener de sus derechos como contribuyentes y de los medios para ejercerlos y hacerlos valer; de la disponibilidad de un servicio eficaz y eficiente de acceso a la justicia en donde el organismo se constituye como un mecanismo no jurisdiccional de defensa de los contribuyentes, especialmente respecto de los procedimientos de quejas o reclamaciones y de acuerdos conclusivos, dirigidos en especial para las personas que se encuentran en situación de desventaja y que acuden ante el organismo para ser atendidas en forma gratuita, ofreciéndoles un servicio de acceso a la justicia propiamente dicho. ${ }^{41}$

Porque el derecho al acceso a la justicia debe tener como finalidad el poder alcanzar la efectividad de una multitud de derechos, especialmente porque en materia tributaria "la complejidad de los recursos administrativos y la poca disposición que existe de las autoridades a efectuar una verdadera revisión y depuración de sus actos antes que los conozca el órgano jurisdiccional, constituye una dificultad estructural para: garantizar el derecho de los contribuyentes a recibir justicia en materia fiscal..$^{42} \mathrm{Y}$ poca utilidad tiene que el Estado reconozca formalmente un derecho si su titular no puede acceder en forma efectiva al sistema de justicia para obtener la tutela de dicho derecho. ${ }^{43}$

Por ello, podemos clasificar las acciones ${ }^{44}$ que está implementando la PRODECON para tutelar el derecho de acceso a la justicia con el uso de las TIC de la siguiente manera:

- La promoción de la cultura jurídica y el acceso a la información vinculada a la prevención de violaciones a los derechos del contribuyente;

- Consulta y asesoría;

- $\quad$ Representación y defensa legal;

- Quejas y reclamaciones; y

\footnotetext{
${ }^{41}$ LILLO LOBOS, Ricardo, et. al., Mecanismos alternativos al proceso judicial para favorecer el acceso a la justicia en América Latina, Chile, Centro de Estudios de Justicia de las Américas (CEJA-JSCA), 2014, p. 17.

${ }^{42}$ BERNAL LADRÓN DE GUEVARA, Diana Rosalía, NAVA RAMÍREZ, Verónica, et. al., Principales problemas de los contribuyentes en el acceso a la justicia fiscal, México, Procuraduría de la Defensa del Contribuyente, 2015, p. 7.

${ }^{43}$ XIV Cumbre Judicial Iberoamericana, 2008. http://www.cumbrejudicial.org/html-cumbres/xiv_cumbre_ judicial/asamblea.html

${ }^{44}$ Políticas públicas que se convierten en una obligación positiva del Estado al eliminar los obstáculos en el acceso a la justicia.
} 
- Celebración de acuerdos conclusivos.

Acciones que se encuentran previstas en el Plan Nacional de Desarrollo (PND) 2013-2018, cuyo propósito es el de contribuir de manera más eficaz, a que México alcance su máximo potencial mediante una serie de estrategias transversales para para alcanzar un gobierno cercano y moderno ${ }^{45}$ y que a continuación describiremos.

\section{VI.1. LA PROMOCIÓN DE LA CULTURA JURÍDICA Y EL ACCESO A LA INFORMACIÓN VINCULADA} A LA PREVENCIÓN DE VIOLACIONES A LOS DERECHOS DEL CONTRIBUYENTE

El acceso al conocimiento que las personas deben tener sobre sus derechos como contribuyentes y de los medios para hacerlos valer, generan una cultura jurídica, y es mediante el uso y la implementación de las TIC que la PRODECON difunde de manera permanente el contenido y alcance de las normas tributarias, los límites de las autoridades fiscales, los medios de defensa del contribuyente, así como los derechos y obligaciones de los pagadores de impuestos a través de materiales didácticos, campañas de comunicación, entre otros.

De ahí que la PRODECON está llevando a cabo esta actividad a través de su portal de internet en donde se encuentra la información necesaria para brindar las herramientas para que las personas puedan tomar mejores decisiones al ejercer sus derechos como contribuyentes.

De igual manera lo está haciendo con las redes sociales, ya que, por medio de Facebook, Twitter y Youtube, el organismo mantiene contacto permanente con las personas quienes buscan recibir orientación o asesoría, presentar una queja o reclamación, para obtener información sobre sus derechos, o bien de las acciones que realiza en su defensa, entre otros. Además, en estas social media se publican productos como los podcast (audios), los webcast (videos animados) y artículos de interés.

PRODECON también se suma como institución a la estrategia de movilidad e innovación con el uso de las TIC en beneficio de las necesidades de las sociedades modernas, creando una App (aplicación) que consiste en una herramienta gratuita y amigable para acercarse a los pagadores de impuestos, constituyéndose como una vía más de contacto para que de manera fácil e intuitiva el contribuyente acceda a la información y pueda solicitar los servicios de información correspondientes. ${ }^{46}$

Como se observa el fomento y la difusión de la cultura jurídica en esta materia es una de las principales herramientas para superar diversas problemáticas del sistema tributario y el acceso a la justicia, ya que permite eliminar barreras como la distancia, la falta de conocimiento y además mejora la relación entre el Estado y los contribuyentes, pues La cultura contributiva representa un nuevo pacto social que permite mejorar la relación entre las autoridades fiscales y los contribuyentes, al promover el respeto irrestricto de los derechos $y$ las obligaciones tributarias, como una cuestión de ciudadanía solidaria, con el objeto de despertar el sentido de pertenencia a México e incidir en el ánimo de los actores de la relación jurídico-tributaria. ${ }^{47}$

Por tanto, el uso de las TIC para acercar el conocimiento a los contribuyentes o pagadores de impuestos, forma parte del acceso a la justicia digital, ya que genera condiciones de

\footnotetext{
$\overline{45}$ Plan Nacional de Desarrollo 2013-2018, México, Presidencia de la República.

${ }^{46}$ http://www. Prodecon.gob.mx/index.php/home/hm/descarga-la-app-prodecn

47 Plan Nacional de Desarrollo 2013-2018, Justificación del Objetivo No. 4 de PRODECON.
} 
confianza y certeza jurídica, permitiendo que sean eliminados los obstáculos que impiden la consecución de la propia justicia, y como lo señala Mariano Fernández Valle es necesario desarrollar una alfabetización jurídica de los diferentes sectores de la sociedad ${ }^{48}$ para que el Estado garantice el respeto y la promoción de los derechos.

\section{VI.2. CONSULTA Y ASESORÍA ${ }^{49}$}

La complejidad del sistema tributario en nuestro país, dificulta en muchas ocasiones el cumplimiento adecuado de las obligaciones, de ahí la necesidad de que la PRODECON a través de sus diversas atribuciones, auxilie a los pagadores de impuestos. Así, por ejemplo, mediante el servicio de consulta, los contribuyentes pueden preguntar cómo deben interpretarse las disposiciones normativas en materia fiscal; de igual manera, a través del servicio de asesoría, el organismo puede ayudar a los contribuyentes cuando son objeto de algún acto de autoridad fiscal y no saben cómo actuar al respecto porque no comprenden los alcances de las disposiciones fiscales.

En este servicio el uso de las TIC desempeñan un papel fundamental, toda vez que en el portal de internet de la PRODECON ${ }^{50}$ se proporciona información suficiente para acceder y conocer qué tipo de asesoría se brinda a las personas físicas, personas morales y obligados solidarios que se ven afectados por créditos fiscales cuyo monto histórico (sin contar actualizaciones, accesorios y multas) no exceden de 30 veces el salario mínimo del Distrito Federal elevado al año (\$799,788.0o para 2016), emitidos por autoridades fiscales federales, incluso las coordinadas en las entidades federativas, así como organismos fiscales autónomos, tales como el Instituto Mexicano del Seguro Social y el Instituto del Fondo Nacional de la Vivienda para los Trabajadores.

Además, en el portal se facilita el acceso a la información con una serie de preguntas y respuestas como: ¿a quienes defiende PRODECON mediante el servicio de representación legal? ¿En dónde puedo solicitar los servicios de la PRODECON? ¿Cómo me defiende la PRODECON? ¿Cuál es la función de los asesores jurídicos? ¿Cómo me puedo enterar del estado que guarda mi asunto? ¿Qué pasa si pierdo el recurso o el juicio?, entre otras, para conocer los planteamientos o problemáticas de los contribuyentes que deriven de actos de autoridad que los involucren.

Otra de las modalidades de atención con el uso de las TIC, es la asesoría vía telefónica sin costo y por correo electrónico, en la que se indica que para solicitar el servicio, el contribuyente deberá proporcionar toda la información y en su caso documentación con el

\footnotetext{
${ }^{48}$ BIRIGIN, Haydée y KOHEN, Beatriz (comps.), Acceso a la justicia como garantía de igualdad. Instituciones, actores y experiencias comparadas, editorial Biblios, 2006, p. 10.

49 El desahogo de estos servicios se sigue bajo los lineamientos que regulan el ejercicio de las atribuciones sustantivas de la Procuraduría de la Defensa del Contribuyente.

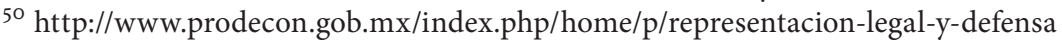


propósito de que su asunto sea analizado y se determine el servicio que el organismo deberá proporcionarle.

También, con la App (aplicación), a través de cualquier dispositivo móvil, los contribuyentes o pagadores de impuestos establecen contacto de manera fácil e intuitiva con el organismo pudiendo solicitar los servicios de asesoría y consulta. ${ }^{51}$

El acceso a la justicia a través de este servicio se ve materializado, ya que los asesores jurídicos de la PRODECON, se encuentran facultados para interponer los recursos administrativos, o bien, para promover el juicio contencioso administrativo ante el Tribunal Federal de Justicia Fiscal y Administrativa, según convenga a los intereses del propio contribuyente, así como el juicio de amparo ante los Juzgados y Tribunales del Poder Judicial de la Federación, cuando así proceda, haciendo valer las acciones, excepciones, incidentes, recursos o cualquier otro trámite o gestión que resulte procedente conforme a derecho y que sea necesario para una eficaz defensa, gestionando, en todo caso, el cumplimiento de las resoluciones que reconozcan los derechos de los contribuyentes en los términos de los procedimientos aplicables.

Una de las ventajas de estos servicios, es que, aun cuando se realizan a través de medios electrónicos, su atención es personal y gratuita, y se otorga al contribuyente o pagador de impuestos en el momento en que éste expone su situación o problemática y entrega en su caso, la documentación en que apoye su solicitud.

El procedimiento en sí, es el siguiente:

- El asesor atenderá la solicitud de asesoría en el momento en que se presente, salvo que requiera mayor análisis debido a la complejidad del asunto, o por el volumen de la documentación que el solicitante proporcione.

- De ser posible, el asesor brindará la asesoría respectiva y en caso de detectar que es necesario que otra Unidad Administrativa de la Procuraduría intervenga para apoyar al solicitante, lo remitirá a la que corresponda para el apoyo respectivo.

El tiempo de respuesta es de tres días hábiles, en cambio si se tratara de emitir un dictamen o acuerdo por escrito sobre una consulta, éste deberá emitirse en un plazo no mayor a veinte días hábiles contados a partir del día siguiente a la fecha de presentación de la consulta.

En el supuesto de que un asesor no cuente con los elementos necesarios como información y/o documentación para brindar la asesoría respectiva, requerirá (al mismo correo electrónico) al solicitante la documentación e información correspondiente, hasta por dos ocasiones, con el apercibimiento de dar por concluido el servicio en caso de no dar cumplimiento al mismo.

Como se aprecia, uno de los beneficios del uso de las TIC en la asesoría y consulta, parte de la tutela del derecho humano al desarrollo, ya que está diseñado para que el acceso a la justicia se desenvuelva a partir del contexto de desigualdad social y económica, pues quienes se ven más beneficiados con este servicio, son sin duda las personas que se encuentran en desventaja económica para acceder a un servicio de asesoría legal, pudiendo obtener las respuesta a todas las preguntas, o bien toda la información que requieran para enfrentar sus

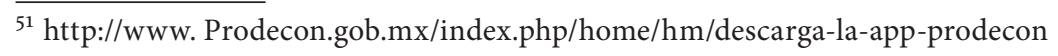


problemas con una explicación completa de los derechos y obligaciones, además de saber que si se requiere contarán con la defensa legal correspondiente.

Asimismo, el servicio de consulta y asesoría con uso de las TIC presenta otras ventajas como la disponibilidad horaria y la comodidad, ya que ésta puede solicitarse en cualquier momento y a cualquier hora con la facilidad que brinda la tecnología al accesar a internet, evitando citas y reuniones o el tener que depender de la disponibilidad del tiempo que una asesoría o consulta pueden ofrecer; la certeza de que toda la documentación permanece con el contribuyente, ya que solo se remite su reproducción en forma digital; la economía, primero, porque recibir la asesoría en línea es un servicio gratuito, y segundo porque se evitan los gastos que se generan por traslados optimizándose el tiempo.

Por tanto, la prestación de los servicios de asesoría y consulta con el uso de las TIC, permitirán en forma gradual y progresiva ir fortaleciendo las bases no solo de una nueva cultura contributiva por parte de los pagadores de impuestos, sino también del conocimiento en la defensa de sus derechos, lo que favorece a una renovada relación entre los contribuyentes y las autoridades fiscales.

\section{VI.3. REPRESENTACIÓN Y DEFENSA LEGAL}

La defensa adecuada es un derecho humano que se conforma dentro del debido proceso como un medio para asegurar en la mayor medida posible, la solución justa de una controversia en la que contribuyen el conjunto de actos de diversas características generalmente reunidos bajo el concepto de debido proceso legal. ${ }^{2}$ Ese conjunto de actos sirven para proteger, asegurar, o hacer valer la titularidad o el ejercicio de un derecho y son condiciones que deben cumplirse para asegurar la adecuada defensa de aquellos cuyos derechos u obligaciones están bajo consideración $[\ldots] . . .^{53}$

Para ello, la Constitución Política en el artículo 17 consagra implícitamente el derecho humano a la defensa legal que deberá ser provisto por el Estado como un servicio de calidad, servicio que no deberá ser entendido como un derecho exclusivo de la materia civil o penal, sino que su alcance debe extenderse a todas las materias.

Es así, que la PRODECON garantiza este derecho humano a través de asesores jurídicos con experiencia acreditada en materia fiscal, brindando al contribuyente o pagador de impuestos una defensa especializada, hasta la conclusión del asunto que se trate, incluyendo la defensa y representación ante el Tribunal Federal de Justicia Fiscal y Administrativa, así como ante los órganos jurisdiccionales del Poder Judicial de la Federación.

Generalmente, este servicio es derivado del servicio de asesoría al que ya hemos hecho referencia, en donde una vez que el asunto expuesto fue analizado, el organismo representa y defiende gratuitamente a las personas físicas, personas morales y obligados solidarios, que

\footnotetext{
${ }^{2}$ Corte IDH, el derecho a la información sobre la asistencia consular en el marco de las garantías del debido proceso legal, Opinión Consultiva OC-16/99 del 10 de octubre de 1999. http://www.corteidh.org.cr/casos.cfm. 3 de octubre del 2016.

53 Corte IDH, Garantías judiciales en Estado de Emergencia (arts. 27.25 y 8 Convención Americana sobre Derechos Humanos), Opinión Consultiva OC-9/87 del 6 de octubre de 1987. http://www.corteidh.org.cr/casos. cfm. 3 de octubre del 2016.
} 
se ven afectados por créditos fiscales cuyo monto histórico no exceden de treinta veces el salario mínimo del Distrito Federal elevado al año, emitidos por autoridades fiscales federales.

$\mathrm{Y}$ al igual que en el servicio de consulta y asesoría, los beneficios del uso de las TIC en la representación legal vuelven a presentarse, incluso en la tutela del derecho humano al desarrollo, ya que el servicio está diseñado para que el acceso a la justicia se desenvuelva a partir del contexto de desigualdad social y económica, pues quienes se ven mayormente beneficiados, son sin duda los contribuyentes o pagadores de impuestos que se encuentran en desventaja económica para contar con un representante legal o defensor.

Sin duda la pobreza y las limitaciones económicas para acceder a una defensa adecuada en materia tributaria, y en particular con el acceso a la tecnología y la utilización de sus herramientas (como ya lo analizamos con el juicio en línea ante el TFJFA o el recurso de revocación) son obstáculos que al ser enfrentados por el propio Estado a través de sus instituciones, en este caso la PRODECON hacen efectivos el derecho humano al acceso a la justicia a través de la defensa legal gratuita, así como la garantía constitucional de seguridad jurídica.

\section{VI.4. QUEJAS Y RECLAMACIONES}

Se ha observado que las autoridades fiscales del orden federal cometen actos que contravienen los derechos y garantías de los contribuyentes o pagadores de impuestos, por ello, uno de los objetivos de la PRODECON previstos en el Plan Nacional de Desarrollo 2013-2018 es el investigar y tramitar quejas de contribuyentes afectados por actos de las autoridades fiscales federales, por presuntas violaciones a sus derechos.

De ahí que se constituyó el derecho de los contribuyentes o pagadores de impuestos a presentar una queja o reclamación, que será resuelta como un procedimiento ágil y expedito, para que la PRODECON conozca e investigue los actos emitidos por las autoridades fiscales que se estimen violatorios de sus derechos a efecto de emitir recomendaciones públicas y proponer, en su caso, medidas correctivas.

Al igual que en el servicio de asesoría, el portal de la PRODECON ${ }^{54}$ cuenta con la información suficiente para efecto de conocer ¿Qué es una queja o reclamación? ¿Cuándo se tramita ante PRODECON? ¿Quién puede promover el procedimiento de queja o reclamación? ¿Qué efectos tiene la presentación de una queja o reclamación para el contribuyente? ¿Qué actos pueden ser materia de un procedimiento de queja o reclamación? entre otras, para acceder a las respuestas derivadas de las problemáticas de los contribuyentes.

Este servicio también es gratuito y para su tramitación se puede hacer con el llenado de un formato que podrá ser presentado vía electrónica para que dé inicio al procedimiento.

Los requisitos para promover la queja o reclamación son:

- Nombre del contribuyente o de la persona moral, acreditándose, en este último caso, la representación legal de la sociedad;

- Precisión del acto de la autoridad fiscal que se considera violatorio de los derechos del contribuyente;

- Señalar domicilio para oír y recibir notificaciones, o bien, el correo electrónico del contribuyente;

\footnotetext{
54 http://www.prodecon.gob.mx/index.php/home/p/procedimiento-de-queja-o-reclamacion
} 
- Breve descripción de los hechos y;

- La protesta de decir verdad.

Una vez presentado lo anterior, el procedimiento es el siguiente: la PRODECON analiza si es de su competencia. En caso de ser competente, la queja o reclamación se admite y se requiere a la autoridad involucrada el informe sobre el acto o actos que se le atribuyen. Rendido el informe, la PRODECON analiza los hechos, los argumentos y las pruebas aportadas por las partes y emite un dictamen que contenga: una recomendación pública cuando se compruebe violación a los derechos del contribuyente o un acuerdo de no responsabilidad cuando no se comprueben las irregularidades imputadas a la autoridad responsable.

Un aspecto interesante del servicio, es el hecho de que si el contribuyente o pagador de impuestos desea dar seguimiento del estado que guarda su queja o reclamación, lo podrá hacer solicitando la información a través del medio que más le convenga, y en el tema del uso de las TIC el organismo responde a través del correo electrónico que señaló.

Entre los beneficios que se observan de este procedimiento con la implementación del uso de las TIC, es que da como resultado un ahorro en tiempo y costos, tanto para las autoridades fiscales como para los contribuyentes, aumentando la seguridad jurídica que la utilización de medios electrónicos ofrece.

Y como ya lo hemos mencionado, el acceso a la justicia se enfrenta a una serie de obstáculos y la falta de confianza en las instituciones es uno de esos, por lo que consideramos que con este servicio la PRODECON intenta distinguirse como una institución confiable, eficaz y transparente en la defensa de los derechos de los contribuyentes, observadora e imparcial de las prácticas y conductas de las autoridades fiscales federales, garantizando con ello un medio alternativo para el acceso efectivo a la justicia en materia fiscal, impactando nuevamente en la transformación de las relaciones que se dan entre las autoridades en materia tributaria y los contribuyentes.

Además, representa un ejemplo claro del cómo llevar a cabo una estrategia de transformación basada en las ventajas que aportan las tecnologías, que sin lugar a dudas, traerá en un futuro una gran cantidad de beneficios si se continua con la correcta planeación y ejecución de este servicio que se suma a los procedimientos administrativos que se desahogan vía medios electrónicos.

\section{VI.5. ACUERDOS CONCLUSIVOS ${ }^{55}$}

La falta de medios alternativos para la búsqueda de soluciones a las controversias derivadas de actos tributarios condujo a una excesiva judicialización de controversias en la materia. De acuerdo con el Informe Tributario y de Gestión para el Tercer Trimestre de 2013, elaborado por el SAT, el número de juicios interpuestos en primera instancia durante el periodo de enero-septiembre 2013 ascendió a 25 mil 862, mientras que fueron un total de 11 mil 946

\footnotetext{
${ }^{55}$ Esta figura se incorporó a las facultades de la PRODECON el 10 de enero del 2014. Artículos del 99 al 107 de los Lineamientos que regulan el ejercicio de las atribuciones de la Procuraduría.
} 
juicios en segunda instancia para el periodo de referencia, lo que da cuenta de la excesiva judicialización de los conflictos. ${ }^{56}$

Situación que provocó que el Estado definiera en el Plan Nacional de Desarrollo 2013-2018 como uno de los objetivos de la PRODECON, el propiciar la solución anticipada y consensuada de los diferendos y desavenencias que puedan surgir entre contribuyentes auditados $\mathrm{y}$ autoridades fiscales.

Por ello se introdujeron al bagaje de derechos en materia tributaria los acuerdos conclusivos $^{57}$ como un medio alternativo de solución de diferencias en el sistema, cuya finalidad es que autoridades y contribuyentes o pagadores de impuestos lleguen a un acuerdo sobre la calificación de hechos u omisiones detectados por las autoridades revisoras dentro de los procedimientos de comprobación, antes de la determinación de un crédito fiscal..$^{58}$

Con este medio alterno, si el contribuyente o pagador de impuestos sujeto a un procedimiento de comprobación de una autoridad fiscal ${ }^{59}$ desea solicitar un acuerdo conclusivo, es necesario que la autoridad revisora hubiera consignado alguna calificación sobre hechos $\mathrm{u}$ omisiones, que pueda entrañar incumplimiento de las disposiciones fiscales, ya que con dichos acuerdos lo que se busca es que la PRODECON promueva, transparente y facilite la solución anticipada, consensuada y definitiva de los diferendos y desavenencias que puedan surgir entre la autoridad y los contribuyentes.

Respecto al desarrollo del procedimiento con el uso de las TIC, el acceso a la información vuelve a desempeñar un papel importante, ya que el portal de la PRODECON ${ }^{60}$ ofrece información suficiente para efecto de conocer ¿Qué es una auditoría o revisión fiscal? ¿A qué está expuesto un contribuyente con una revisión fiscal? ¿Qué puede hacer un contribuyente si no está de acuerdo con los hecho u omisiones consignados por los auditores o visitadores durante una revisión fiscal? entre otras preguntas, para acceder a las respuestas derivadas de las problemáticas de los contribuyentes.

Otra de las ventajas que ofrece el organismo con la implementación de las TIC en sus servicios, es el hecho de que para tramitarlo se puede solicitar previamente la asesoría en línea dando clic en el portal del organismo, y para su tramitación se puede hacer con el llenado del formato de Acuerdo Conclusivo que se encuentra en el portal de la PRODECON.

Para iniciar el procedimiento, es necesario que el contribuyente presente la solicitud llenando el formato al que ya nos hemos referido, a través de correo electrónico, que incluya:

- El nombre, domicilio y registro federal del contribuyente;

- En caso de que comparezca mediante representante legal, que éste cuente con poder general para actos de administración, de dominio o bien con poder especial para la suscripción de los Acuerdos Conclusivos previstos en el Código Fiscal de la Federación(adjuntando copia certificada de la escritura en que conste);

- La designación, en su caso, de autorizados para oír y recibir notificaciones, así como el domicilio que se señale para ese efecto;

\footnotetext{
${ }^{56}$ Diagnóstico de la PRODECON en el Plan Nacional de Desarrollo 2013-2018, México, Presidencia de la República.

57 Entraron en vigor el $1^{\circ}$ de enero del 2014.

${ }^{8}$ Diagnóstico de la PRODECON, Op. Cit., nota. no. 56.

${ }^{59}$ SAT, IMSS, Tesorerías o Recaudaciones locales, entre otras.

${ }^{60} \mathrm{http}: / /$ www.prodecon.gob.mx/index.php/home/p/procedimiento-de-queja-o-reclamacion
} 
- Que el escrito sea dirigido a la PRODECON y firmado por el contribuyente o su representante legal;

- La mención e identificación precisa de los hechos u omisiones calificados por la autoridad revisora con los cuales no esté de acuerdo;

- La calificación que pretende se dé a los hechos u omisiones respecto de los que solicita la adopción del Acuerdo, expresando los argumentos de fondo y razones jurídicas que la sustenten y, en consecuencia;

- Los términos precisos con los que pretende que la autoridad acepte el Acuerdo Conclusivo.

- La mención de que, en todo lo manifestado, comparece bajo protesta de decir verdad.

Una vez recibida la solicitud de Acuerdo Conclusivo, la PRODECON, en un plazo máximo de tres días hábiles, procederá a admitirla e identificará los hechos u omisiones calificados por la autoridad revisora, respecto de los cuales el contribuyente solicita la adopción del Acuerdo Conclusivo y requerirá a dicha autoridad para que, en un plazo máximo de veinte días hábiles, contados a partir del día siguiente a aquel en que surta efectos la notificación del requerimiento, produzca su contestación.

La autoridad revisora, al producir su contestación, podrá:

- Manifestar si acepta los términos del Acuerdo Conclusivo;

- Expresar con precisión, fundando y motivando, los diversos términos en que procedería su adopción;

- No aceptar los términos en que se plantea el Acuerdo, en cuyo caso deberá expresar los fundamentos y motivos de su negativa;

- Acompañar la información y documentación que considere relevante sobre la calificación de los hechos u omisiones a los que se refiera la solicitud de adopción de Acuerdo Conclusivo;

El organismo al recibir la contestación de la autoridad revisora emitirá, en un plazo máximo de tres días hábiles, el acuerdo de recepción respectivo, en el cual dará cuenta de dicha contestación. Si la autoridad acepta la adopción del Acuerdo Conclusivo turnará de inmediato el expediente al área respectiva para que ésta proceda, en un plazo máximo de siete días, a la elaboración del proyecto del Acuerdo Conclusivo, lo que se notificará a las partes.

El acuerdo así emitido por la PRODECON será comunicado a la autoridad y notificado personalmente al contribuyente en un plazo máximo de cinco días hábiles, para efectos de que éste manifieste, en igual plazo, si acepta o no los diversos términos en que la autoridad propone la adopción del Acuerdo Conclusivo. El plazo otorgado al contribuyente iniciará a partir del día siguiente a aquel en que surta efectos la notificación respectiva.

Como se aprecia, esta medida alternativa de solución de controversias en materia fiscal representa una nueva forma impartir justicia y su instrumentación a través del uso de las TIC propicia una relación más ágil, directa y expedita debido a la celeridad en el tiempo que se desarrolla el procedimiento entre autoridades y contribuyentes, en la cual la PRODECON 
implementa y realiza sus mejores acciones como órgano técnico especializado en materia fiscal, para que ambas partes lleguen a un acuerdo que ponga solución a sus diferencias.

Con los acuerdos conclusivos, la PRODECON hace efectivo el derecho humano al acceso a la justicia con la defensa a través de medios alternativos de solución de controversias en términos de lo previsto por el artículo 17 de la Constitución Política y garantiza la seguridad jurídica. Además, con estos, el organismo transparenta la emisión de los acuerdos conclusivos, pues funge como facilitadora y testigo de los mismos, velando en todo momento por el respeto a los derechos de los contribuyentes y el cumplimiento de las disposiciones jurídicas aplicables.

Como lo expresamos en el apartado anterior con el procedimiento de quejas, los acuerdos conclusivos también representan un ejemplo de cómo se lleva a cabo una estrategia de transformación basada en las ventajas que aportan las TIC, en la que sin dudas será necesario potenciar su utilización para que se advierta como una acción efectiva en la solución de controversias sin necesidad de acudir a la vía jurisdiccional.

Finalmente, es importante que mencionemos que con estas acciones, el acceso a la justicia fiscal mejora progresivamente. Por ello, la Procuraduría de la Defensa del Contribuyente está cumpliendo con los compromisos internacionales suscritos por México, en donde la protección, defensa y observancia de los derechos de los contribuyentes o pagadores de impuestos, es una labor que está quedando plasmada en su quehacer institucional como defensor permanente del contribuyente o pagador de impuestos.

\section{CONCLUSIONES}

Primera: Para tutelar efectivamente los derechos de los contribuyentes, resulta fundamental el papel que desempeñan las autoridades, por ello, es importante la adopción de medios eficaces que aminoren la judicialización de las controversias surgidas entre la autoridad fiscal y los contribuyentes, por lo que el esfuerzo que se hace a través de la PRODECON con el uso de las TIC es la manera que permite a cualquier persona tener acceso a la justicia en forma sencilla, gratuita y sin tantas formalidades.

Segunda: Una acción importante con la implementación del uso de las TIC que favorece el derecho de acceso a la justicia se observa con las políticas introducidas por el SAT y la puesta en marcha del juicio en línea de parte del TFJFA para agilizar el desahogo de los procedimientos, así como las herramientas tecnológicas que facilitan la promoción del juicio contencioso.

Así también las políticas que se están implementando con el uso de las TIC están coadyuvando en la generación de confianza por parte de los contribuyentes, pues la orientación y la asesoría en línea hacen que sea sencillo y fácil el cumplir con sus contribuciones o bien el advertir en su vida cotidiana que sus tributos son justos, y que cuando se lleva a cabo una vulneración de sus derechos por parte de la autoridad fiscal encuentre una adecuada defensa 
legal que no le represente mayores costos debido a la gratuidad y la disponibilidad de los procedimientos en línea que ofrece principalmente la PRODECON.

Tercera: El derecho de acceso a la justicia en línea debe ser alcanzable para todos con independencia de sus circunstancias personales, medios económicos o conocimientos; un acceso que resulte un proceso ágil y sencillo, que permita que el derecho de acceso a la justicia se convierta en la tutela efectiva a los derechos y libertades públicas.

VIII. FUENTES DE INFORMACIÓN

ÁVILA DÍAZ, William Darío, "Hacia una reflexión histórica de las TIC", en Revistas Ustas, Colombia 2012. http://revistas.usta.edu.co/index.php/hallazgos/article/download/751/1031

BERNAL LADRÓN DE GUEVARA, Diana Rosalía, NAVA RAMÍREZ, Verónica, et. al., Principales problemas de los contribuyentes en el acceso a la justicia fiscal, México, Procuraduría de la Defensa del Contribuyente, 2015.

CUMBRE JUDICIAL IBEROAMERICANA, XIV Cumbre, 2008. http://www.cumbrejudicial.org/html-cumbres/xiv_cumbre_judicial/asamblea.html

DE LA GARZA, Sergio, Derecho Financiero Mexicano, México, Porrúa, 2001.

JIMÉNEZ HERNÁNDEZ, Maricela, El Recurso de Revocación como Alternativa de Defensa para el Particular.

http://www.tffa.gob.mx/investigaciones/pdf/recursoderevocacion.pdf

LADRÓN DE GUEVARA, Diana Bernal, Discurso Foro Criterios Jurisdiccionales: La labor de la Procuraduría de la Defensa del Contribuyente como abogado defensor, Agosto del 2014. http://www.prodecon.gob.mx/index.php/home/sala-de-prensa/comunicacion-social/boletines/2014/166-boletines-de-prensa-nacional/2014/8agosto/1223-boletin-nacional-42-2014

LILLO LOBOS, Ricardo, et. al., Mecanismos alternativos al proceso judicial para favorecer el acceso a la justicia en América Latina, Chile, Centro de Estudios de Justicia de las Américas (CEJA-JSCA), 2014.

MARANIELLO, Patricio Alejandro, "las limitaciones económicas al acceso a la justicia", en IUS Revista del Instituto de Ciencias Jurídicas de Puebla A.C., No. 21, 2008, pp. 98-118.

MONTORO VALLESTEROS, Alberto, El funcionalismo en el Derecho, notas sobre N. Luhmann y G. Jakobs, Anuario de Derechos Humanos, Novena época, vol. 8, 2007.

https://revistas.ucm.es/index.php/ANDH/article/viewFile/ANDHo707110365A/20789

MORALES NAVARRO, Katia, "La inclusión de las tecnologías en la gestión judicial", en Sistemas Judiciales. Una perspectiva integral sobre la Administración de Justicia, Año 9, No. 16, Chile, Centro de Estudios de Justicia de las Américas (CEJA). 2011. http:// www.sistemasjudiciales.org/content/jud/archivos/revpdf/78.pdf 
NÁJERA MARTÍNEZ, Alejandro, Derecho Tributario, México, Tecnológico de Estudios Superiores del Oriente del Estado de México, 2012. http://www.upg.mx/wp-content/ uploads/2015/10/LIBRO-42-Derecho-Tributario.pdf

ORGANIZACIÓN DE LAS NACIONES UNIDAS, Informe del Consejo Económico y Social, Quincuagésimo quinto período de sesiones No. A/55/3, 2000. http://www.itu. int/wsis/docs/background/resolutions/55-3-es.pdf

PETRACHI, Enrique, Acceso a la justicia, en: La Ley, 27 de mayo de 2004.

PONCE GÓMEZ, Francisco, Derecho Fiscal, México, Editorial Banca y Comercio, 1994.

PRODECON, "Naturaleza de la Procuraduría de la Defensa del Contribuyente como obudsman (el papel de los defensores no jurisdiccionales de derechos)", en sede de cuadernos de la Procuraduría de la Defensa del Contribuyente, México, Procuraduría Federal del Contribuyente, No. XI, 2016.

http://www.prodecon.gob.mx/index.php/home/cc/publicaciones/numero-xi

ROMERO MICHEL, Jessica Cristina, et. al., "Aproximaciones Teóricas en la implementación de uso de las Tecnologías de la Información y las Comunicaciones (TIC) en la Administración de Justicia en México", en De Jure, Mayo de 2016, México, Universidad de Colima.

SERRANO ANTON, Fernando, El régimen jurídico de la defensa del contribuyente del Ayuntamiento de Madrid: Hacia una administración orientada al servicio del contribuyente, España-México, Fontamara, 2013.

SUPREMA CORTE DE JUSTICIA, Libro Blanco de la Reforma Judicial: Una agenda para la Justicia de México, México, Suprema Corte de Justicia-Poder Judicial, 2006.

ZAMBRANO, Raúl, “Uso de las TIC en materia de asistencia al contribuyente”, en: Revista de Administración Tributaria, CIAT/AEAT/IEF, No. 35, Junio de 2013.

DISPOSICIONES JURÍDICAS

México, Código Fiscal de la Federación, 2016.

México, Constitución Política de los Estados Unidos Mexicanos, 2016.

México, Ley Federal de los Derechos del Contribuyente, 2016.

México, Ley Federal del Procedimiento Contencioso Administrativo, 2016.

México, Lineamientos que regulan el ejercicio de las atribuciones de la Procuraduría de la Defensa del Contribuyente, 2016.

México, Programa Institucional 2013-2018 de la Procuraduría de la Defensa del Contribuyente.

http://www.dof.gob.mx/nota_detalle.php?codigo=5344994\&fecha=16/05/2014 
